\title{
Sustainability and Global Logistics
}

Author(s): Seung Bum Ahn, Junjae Chae

Source: Journal of International Logistics and Trade 2019; 17(2):42

Published by: Jungseok Research Institute of International Logistics and Trade, Inha University

DOI: https://doi.org/10.24006/jilt.2019.17.2.042

The Journal of International Logistics and Trade is an official journal published by Jungseok Research Institute of International Logistics and Trade, Inha University, Korea. JILT welcomes manuscripts that advance the practice and science of logistics, trade, and other related fields.

Frequency: Quarterly (March, June, September, December)

Stable URL: https://www.ejilt.org

The Jungseok Research Institute of International Logistics and Trade is a specialized academic research institute representing Inha University and the Inha Foundation in Korea. The institute aims to become a representative institute in Northeast Asia in the research of logistics and trade.

Stable URL: https://jrieng.inha.ac.kr

(C) Copyright. Jungseok Research Institute of International Logistics and Trade.

This is an Open-Access article distributed under the terms of the Creative Commons Attribution NonCommercial License (http://creativecommons.org/licenses/by-nc/4.0/) which permits unrestricted noncommercial use, distribution, and reproduction in any medium, provided the original work is properly cited 


\section{Journal of \\ International Logistics and Trade}

\section{Editorial}

\section{Sustainability and Global Logistics}

The importance of global logistics is increasing due to the increase of trade among countries and the investment of multinational corporations. In addition to the intermodal transportation system that links the port, airport, and inland logistics bases with the increase in cargoes through e-commerce, trends such as increasing trade in fresh food and increasing importance of reverse logistics are undergoing changes. Environmental issues such as fine dust, ballast water and fuel consumption, and the development and operation of sustainable infrastructure are emerging as issues among countries. In this regard, a special issue is planned to cover "sustainability and global logistics".

There are different problems in different countries and regions and different solutions, but they also face the same problems or issues that need to be addressed jointly. There are technological and industrial changes such as the 4th Industrial Revolution and AI, IoT, autonomous driving, and shared economy, the traditional social values such as urban problems, birth and employment problems, welfare and quality of life. In addition, how to maintain it becomes an important issue. In this special issue, we tried to provide an opportunity to expand the general approaches to other regions and societies through researches on national and regional logistics.

The first paper, "Analyzing the costs and benefits of installing unmanned parcel lockers: Focusing on residential complexes in Korea," written by Hoang Thai Pham and Hyangsook Lee, deals with the increase of courier goods due to a boom of e-commerce in Korea, increasing of the small quantity of multiple items delivered in urban area where the high population density brings about the problems such as traffic congestion, accessibility and pollution. It deals with a final shipping method of the cargo which is the core of last mile delivery in multi-family houses and apartments. A new alternative for home delivery service, parcel locker, were proposed and analyzed its impact in terms of costs and benefit when it comes to the residential area. Although this paper deals with the case of Korea, we may expand to similar problems in other countries and regions where laws and systems are different.

The second paper, "A case study on logistics services preferences for supply chain entities in Shandong province, China," written by Woosuk Seo and Seung Bum Ahn, is on a case in Shandong province of China. Assessment of logistics services in a particular country or region is very important when it comes to improving logistics services in public and private matters and has a guideline on what parts should be raised first and to what extent. In this respect, this study suggests directions in terms of sustainable improvement in international trade and investment including domestic matters. It finds the logistics service factors in supply chain entity in Shandong Province in China and it could be extended to evaluate logistics service attributes which influence overall logistics system. It has been found that four supply chain entities, third party logistics, customs, market, and manufacturers in the region have different service preferences and this would be good reference to the region in similar environment.

In this special issue, two papers are covered with the theme of "sustainability and global logistics". However, there are many current and emerging issues in logistics and supply chain management (SCM). Technological changes, the increasingly interdependence of the cold chain and e-commerce in the global market, and the regulation and co-ordination of fine dust, air pollution and various environmental aspects have also not been addressed in this special issue. The research on logistics and SCM is not a matter that can be solved only in some fields such as technology and optimization or private enterprise when it is treated as a complicated problem through increasing linkage and relationship rather than specificity of a specific region. The international aspect of cooperation across countries is becoming more important. More researches will be needed to find ways to improve, sustain, prepare for, and plan strategies and actions in the short term and mid- and long-term perspectives as well as the global society, the private sector and the public.

Seung Bum Ahn

Graduate School of Logistics, Incheon National University, Incheon, Korea E-mail: sbahn@inu.ac.kr

https://doi.org/10.24006/jilt.2019.17.2.001
Junjae Chae

School of Air Transport, Transportation and Logistics, Korea Aerospace University, Goyang, Korea E-mail: jchae@kau.ac.kr 